\title{
The response of a seasonal snow cover to explosive loading
}

\author{
Jerome B. Johnson, Daniel J. Solie and Stephen A. Barrett \\ U.S. Army Cold Regions Research and Engineering Laboratory, P.O. Box 35170, Fort Wainwright, AK 99703-0170, U.S.A.
}

\begin{abstract}
An explosive detonation in snow produces high intensity shock waves that are rapidly attenuated by momentum spreading as the snow is compacted. Our experimental measurements and numerical calculations indicate that the maximum shock-wave attenuation in seasonal snow $\left(250 \mathrm{~kg} \mathrm{~m}^{-3}\right)$ is proportional to between $x^{-1.6}$ and $x^{-1.5}$ for plane waves and $x^{-3}$ for spherical waves $(x$ is the propagation distance). Outside the region of shock-compacted snow or in air over snow, stresses are transmitted as acoustic/seismic waves. Attenuation of these waves depends on snow permeability and the effective modulus of the ice frame and is proportional to about $x^{-0.7}$ for plane waves in seasonal snow and to about $x^{-1}$ for spherical waves in air over seasonal snow. Increasing the scaled detonation height of an explosive up to $2 \mathrm{~m} \mathrm{kgf}^{-1 / 3}$ above a snow cover increases the far field (scaled distances greater than about $8 \mathrm{~m} \mathrm{kgf}^{-1 / 3}$ ) snow surface pressures. Scaled detonation heights greater than about $2 \mathrm{~m} \mathrm{kgf}^{-1 / 3}$ have little additional effect.
\end{abstract}

\section{INTRODUCTION}

Explosives are used in snow to transmit pressure to snowcovered objects, reduce the hazard of snow avalanches and excavate snow. Effective methods for using explosives in snow have been developed through practical application and experiments. Additional improvements in the effective use of explosives in snow are limited by a lack of quantitative information about how snow responds to explosive loading and adequate models to predict the response of the explosive/snow system. The physical aspects of snow that make determining its response to an explosive difficult include snow's high homologous temperature, low strength, porous structure and high compressibility. In addition, the physical makeup of a snow cover and its surroundings (for example, internal snow layering and substratum material) and the characteristics of a given explosive will affect the stresses and deformations that are transmitted into a snow cover.

An explosive, depending on where it is detonated, can produce shock waves that permanently deform the snow through compaction, produce fractures in the snow and, for large stresses, cause melting. A shock wave propagates as a steep transition zone between undeformed and deformed material and the shear strength of the material can generally be ignored. When stresses in the snow do not cause permanent snow compaction, they are transmitted as acoustic/seismic waves in the interstitial pores and the ice-particle frame. The acoustic/seismic waves are called precursor waves when their propagation velocity is greater than that of a following shock wave. Shock and acoustic waves may also propagate in the air above a snow cover. Snow surface waves and ground seismic waves may also occur, but are not discussed in this paper as they are secondary effects and do not contribute significant stress to the snow cover.

In this paper, we present our measurements of shock wave propagation and attenuation in snow along with our numerical calculations to describe shock waves in snow. We compare rates of attenuation for plane and spherical shock waves in snow, plane acoustic waves in snow and spherical acoustic waves over snow. We use existing data to develop a method for selecting an explosive's weight and detonation height to maximize its effectiveness. In addition, we review earlier work on acoustic wave propagation in snow to present a comprehensive description of snow's response to explosive loading.

\section{EXPLOSIVE DETONATION WITHIN A SNOW COVER}

An explosive detonated in well-sintered snow produces a shock wave that propagates into the snow. Near the explosive, where stresses can approach several GPa, the shock-wave velocity may be greater than the acoustic/ seismic waves that propagate through the snow so that no precursor wave is present. As the shock wave attenuates, its velocity decreases until a precursor acoustic/seismic compression wave and shear wave eventually precedes the shockwave. This acoustic/seismic wave propagates in the ice frame but is coupled to the air in the pore spaces. As the shock-wave velocity continues to decrease a second compressional precursor wave, propagating in the interstitial air pores, but coupled to the ice frame, will 
appear. Eventually the shock stress amplitude will decrease below the level required to cause permanent snow compaction and only the two compression waves and shear wave will remain. In snow that is unsintered, acoustic/seismic waves are not able to propagate through the ice frame and only the second compression wave will be present. This situation may occur for new snow (personal communication from D. G. Albert).

Shock-wave attenuation occurs by momentum spreading. An explosive impulse applies a finite short-duration momentum pulse to snow that results in a high momentum density, pressure and particle velocity. If snow were elastic, the momentum pulse would propagate along unchanged so that for plane waves there would be no momentum spreading and no attenuation. Because snow is permanently compacted by a shock wave, much of the momentum behind the shock front is transferred to the mass of snow rather than being propagated through it. This spreading of the momentum over the mass of snow behind the shock wave front causes the momentum density to decrease with a consequent decrease in pressure and particle velocity. Spherical shock waves attenuate even more rapidly than plane waves because the mass over which the momentum is spread increases in direct proportion to the volume of compacted snow behind the spherical shock front. The attenuation of a spherical shock wave, assuming a simple attenuation model, can range from $x^{-1.5}$ to $x^{-6}$ as compared to $x^{-1.5}$ for plane waves, where $x$ is the propagation distance (Johnson, 1991). The severity of shock-wave attenuation depends on the amount of hysteresis between the compaction-loading path and the release or unloading path, where the release path is determined by the release modulus of the snow. Our previous laboratory experiments have shown that this hysteresis can be quite large (Johnson and others, 1993).

We conducted a series of field tests to determine the magnitude of shock-wave attenuation in snow and to examine the important factors that control the response of a snow cover to an explosive. In these tests, a flat sheet explosive was placed on a snow surface and detonated at several points simultaneously to produce a plane shock wave. We used stress gauges buried at different depths in the snow to measure the shock-wave pressure reduction with propagation distance. The results from these tests show that the magnitude of shock-wave attenuation in snow is very high (Fig. 1). A simple power-law fit to the measured data indicates that the attenuation proceeds approximately as $x^{-1.6}$, which is similar to the $x^{-1.5}$ value predicted by simple theory (Johnson, 1991) when the uncertainty of the field measurements are taken into account. Our examination of recovered snow after each test indicates that the snow compaction is caused by the rearrangement and plastic deformation of ice particles, and melting. Gases generated by an explosive detonation penetrate the snow's interstitial air pores transmitting a strong impulse into the ice particles and air-filled pores. This often results in a thin layer of carbon intermixed with snow in the crater region. The bonds connecting ice particles that constitute the snow are broken by the shock and flow past one another until the snow reaches a critical density, at which point further compaction is by plastic deformation of the ice particles. Near the explosive

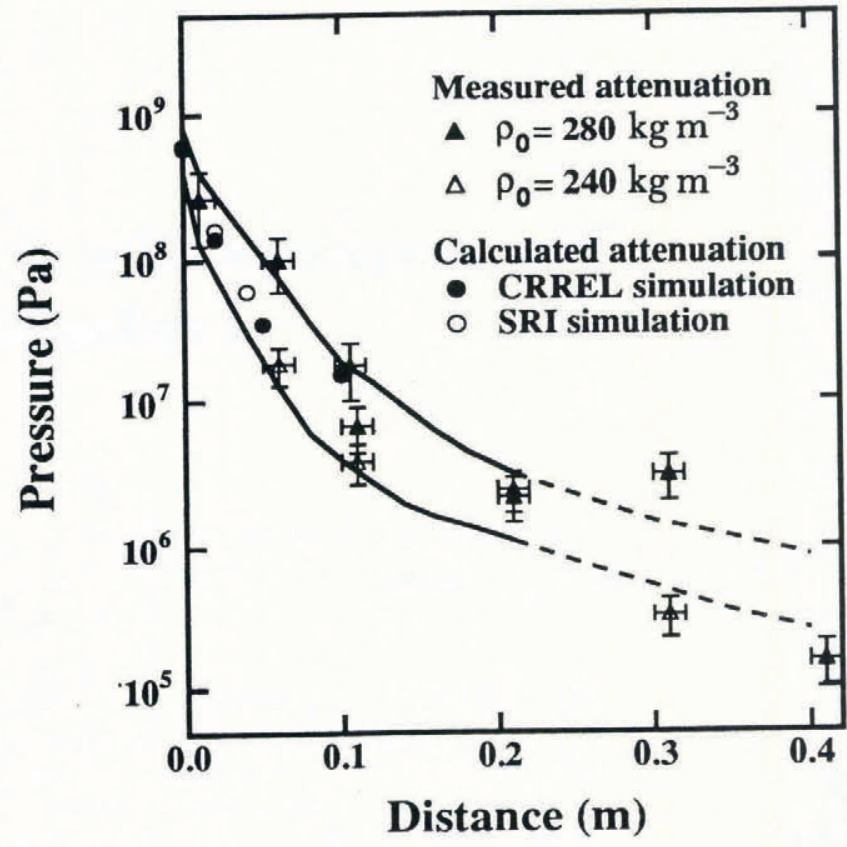

Fig. 1. Comparison of our measurements of planar shockwave pressure attenuation in snow with calculated values. Our calculations (CRREL simulation) were done using the Pronto-2D program and the SRI simulations were done by $L$. Seaman using the PUFF program. Both simulations used shock compaction and release data from Johnson and others (1993).

source, we have observed partial wetting of the snow that may be due to shock heating or conduction heating from the chemical reaction of the explosive. If the impulse of an explosive is completely contained in the snow cover then most of the momentum in the snow is dissipated in the crater region as a result of inelastic deformation. Consequently, little momentum is propagated away from the crater region as acoustic/seismic waves in the ice frame or through the air pore structure.

Simulations of field tests to examine the influence of explosive charge geometry on the reduction of the shock pressure as a function of propagation distance were done using the Pronto-2D finite-element program (Taylor and Flanagan, 1987). In the simulations, the explosive parameters were determined from published values for Dupont manufactured Detasheet (Dobratz and Crawford, 1985) and the data describing the shock response of snow were taken from Johnson and others (1993). The simulation results for the field tests are in good agreement with measured values (Fig. 1).

Calculated results comparing the shock-wave pressure reduction for a plane wave to that of a spherical wave, using the same initial explosive impulse for both is shown in Figure 2. The maximum shock pressure attenuation proceeds approximately as $x^{-3}$ for a spherical wave and $x^{-1.5}$ for a plane wave. The predicted attenuation for plane shock waves using a simple model $\left(x^{-1.5}\right)$ and finite element methods $\left(x^{-1.5}\right)$ agree with each other and with the field measurements $\left(x^{-1.6}\right)$ within the limits of our experimental uncertainty. These results indicate that shock-wave attenuation is predominantly determined by an explosive's impulse and geometry, and the pressure- 


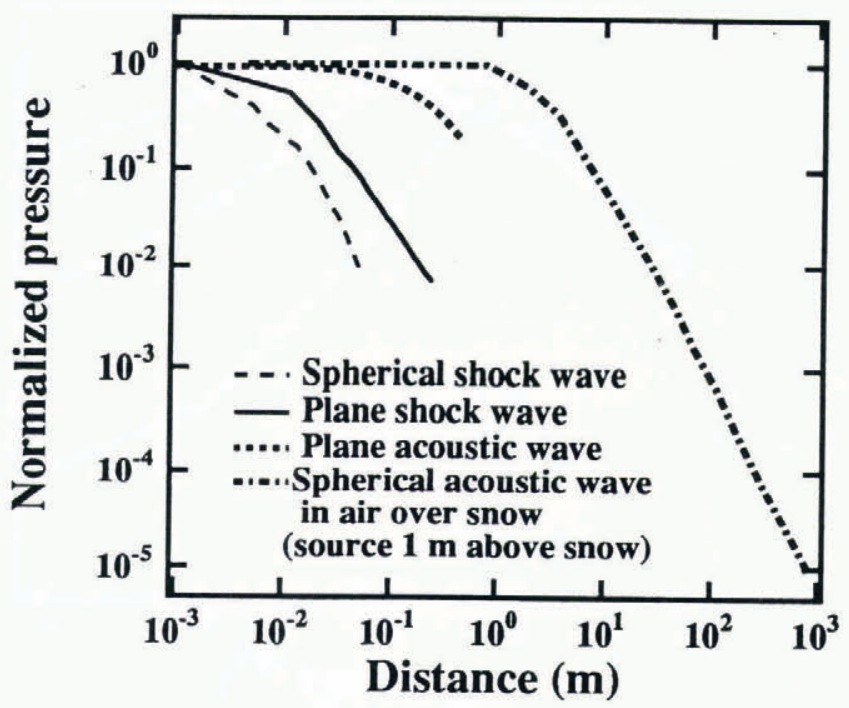

Fig. 2. Calculated normalized pressure attenuation for plane shock and acoustic/seismic waves, spherical shock waves $\left(R_{0}=0.01 \mathrm{~m}\right)$ propagating in snow and a spherical acoustic wave $\left(R_{0}=1 \mathrm{~m}\right)$ propagating over snow. Peak pressure for the shock waves was about $1 \mathrm{GPa}$ with an impulse of about $3 \mathrm{kPa}$. Calculations were done using Pronto-2D and data from Johnson and others (1993). Calculated results from Fohnson (1982) and Albert and Orcutt (1990) were used to determine values for the plane and spherical acoustic waves. The snow density used in the calculations varied from 210 to $290 \mathrm{~kg} \mathrm{~m}^{-3}$.

volume deformation path of snow during loading and unloading. The snow compacts with very little volume recovery producing a large hysteresis between loading and unloading. These results also indicate that the attenuation of shock waves that are completely contained within the snow may be estimated with reasonable accuracy using a simple analytical theory without resorting to finite element methods.

\section{EXPLOSIVE DETONATION ON OR ABOVE A SNOW GOVER}

An explosive detonated on the surface of a snow cover will produce a spherical shock wave in the snow, in which much of the explosive impulse will be absorbed by compacting snow, and a spherical shock wave that propagates in the air over the snow cover. Measurements of the attenuation of air shock waves as a function of radial distance, $R$, from ground zero (the position directly beneath the detonation point) over perennial and seasonal snow indicate that attenuation is proportional to $R^{-2}$ to $R^{-1}$ (Mellor, 1985). When shock pressures are sufficiently reduced the waves propagate and attenuate as acoustic waves (Fig. 2). The attenuation of an air shock over snow occurs because of geometric spreading and absorption into the snow.

Seasonal snow is composed mostly of air and the resistive part of the snow's impedance is similar to that of air. Consequently, a significant amount of the incident energy from an air shock is transmitted into the snow.
Power reflection coefficients for normal incidence acoustic waves vary with frequency, but our calculations, using data from Attenborough and Buser (1988) and Albert and Orcutt (1990), indicate that maximum values of less than 0.5 are typical, and minimum values are near zero. Conversely, calculations of maximum power reflection coefficients for hard pack soil, using data from Attenborough (1985), commonly exceed 0.98 .

Pressure transmission into the snow from the air shock wave will be primarily through the air pores; this is equivalent to the second compressional wave discussed in the preceding section. This wave is coupled to the ice frame and is responsible for producing the peak stresses and motions in the ice frame near the snow surface (Johnson, 1982).

Pressure measurements indicate that explosives detonated in air above the snow produce higher stresses and particle motions in the snow than for explosives buried in the snow or at the snow surface (Ingram, 1962; Wisotski and Snyer, 1966; Joachim, 1967; Gubler, 1977). As the detonation height above the snow cover is increased the pressure at ground zero will decrease. The snow-surface pressure as a function of radial distance from ground zero will, however, initially increase with detonation height to a maximum value and then decrease. In Figure 3 , we relate $H_{\max }$ to $R_{H_{\max }}$, where $H_{\max }$ is the detonation height of an explosive that produces the maximum pressure at a given radius $\left(R_{H_{\max }}\right)$ (maximum pressure curve). $H_{\max }, R_{H_{\max }}$ and $P_{H_{\max }}$ are scaled to explosive weight. We use data from Ingram (1962) and Wisotski and Snyer (1966) summarized in O'Keeffe (1965) and Mellor (1985) for this figure. Ingram's tests were done on perennial deep snow with an average density of about $300 \mathrm{~kg} \mathrm{~m}^{-3}$ in the upper $0.5 \mathrm{~m}$. Wisotski and Snyer's tests were conducted on seasonal snow with snow depths of between 0.2 and $1.2 \mathrm{~m}$ with average snow densities that ranged from 250 to $360 \mathrm{~kg} \mathrm{~m}^{-3}$ in the upper $0.3 \mathrm{~m}$ of snow.

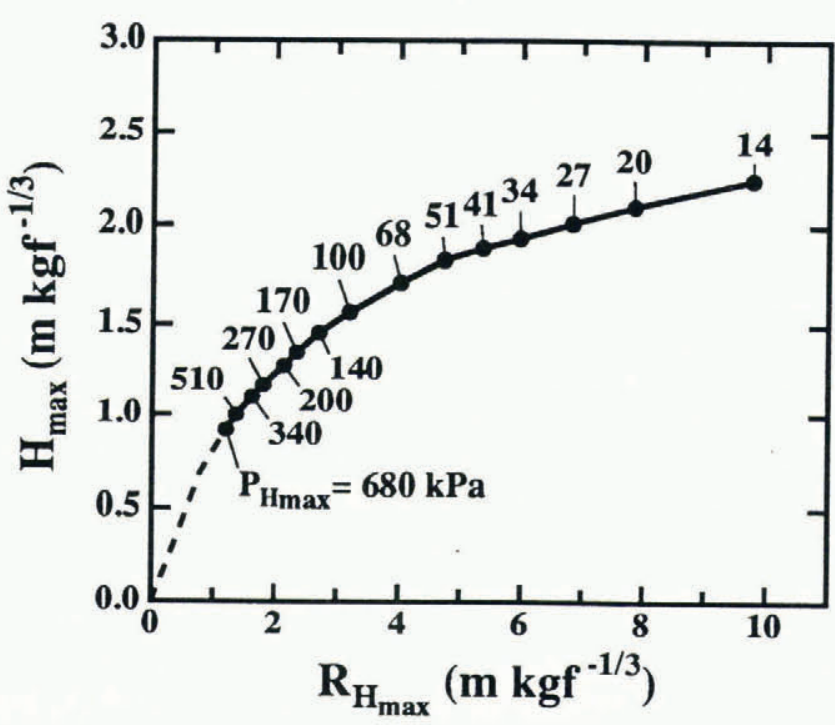

Fig. 3. The maximum pressure curve for perennial and seasonal snow. $H_{\max }$ is the scaled height of detonation that produces the maximum pressure $P_{H_{\max }}$ at a scaled radius of $R_{H_{\max }}$ from ground zero. Labels on the curve represent $P_{H_{\max }}$ at $R_{H_{\max }}$ produced by an explosive detonated at $H_{\max }$. 
Presenting the detonation height and radial distances as scaled against the cube-root of the explosive weight is done to simplify the comparison of explosives of different size. It is a recognition that the energy, and thus the momentum impulse of an explosive, is directly proportional to its weight, and that after detonation, this momentum is spread through an expanding spherical volume. Pressure is a function of the change in momentum density across the shock-wave front. Since the momentum density is proportional to the explosive weight divided by the expanding spherical volume, the radii of equal pressure $\left(r_{1}\right.$ and $\left.r_{2}\right)$ for two explosive charges with different weights are related by the ratio of the cube root of their weights $\left(w_{1}\right.$ and $\left.w_{2}\right), r_{2}=$ $r_{1}\left(w_{2} / w_{1}\right)^{1 / 3}$. Hence, explosives with differing weights, but the same density, specific energy and spherical geometry produce the same pressure at their scaled distances when the medium surrounding an explosive is homogeneous (Baker, 1973).

The scaling relations and the results presented in Figure 3 can be used to determine the actual detonation height of a given weight explosive that is needed to produce the desired maximum pressure at the snow surface beneath the explosive. The detonation height $H$, in meters, for an explosive of weight, $w$, that produces the same pressure as is produced by a scaled detonation height of $H_{\max }$ is given by

$$
\begin{aligned}
H & =w^{1 / 3} H_{\max } \\
\text { and } R & =w^{1 / 3} R_{H_{\max }} .
\end{aligned}
$$

This scaling relationship is applicable for a detonation in air over snow and depends on the maximum pressure curve for snow which may change due to differing snowsurface power reflection coefficients, but will have the same general form as shown in Figure 3.

Gubler (1977) used accelerometer measurements in snow to develop a scaling relationship for explosive detonation in and over snow given by

$$
R=w^{\delta} R_{1 \mathrm{kgf}},
$$

where $R_{1 \mathrm{kgf}}$ is the radius of equivalent pressure for a $1 \mathrm{kgf}$ weight explosive and the value of $\delta$ depends on whether the snow is wet or dry and on the location of the explosive at detonation. ( $\mathrm{kgf}$ is commonly used to represent the weight of an explosive. To convert to Newtons multiply by 9.8 .) For detonation on or above the snow surface $\delta$ equals $1 / 2$ for dry snow and equals $1 / 4$ for wet snow. The scaling relationship is assumed to be independent of detonation height. Because maximum pressure curves were not determined for Gubler's experiments and differences in ambient air pressure between the different data sets can affect scaled results, it is difficult to directly compare Equation (2) scaling with that given in Equation (1). The fact that the value of $\delta$ differs for dry and for wet snow, however, gives an indication of the magnitude of change that can occur in snow pressure or particle velocity due to changes in snow conditions. While the assumption that Equation (2) is unrelated to

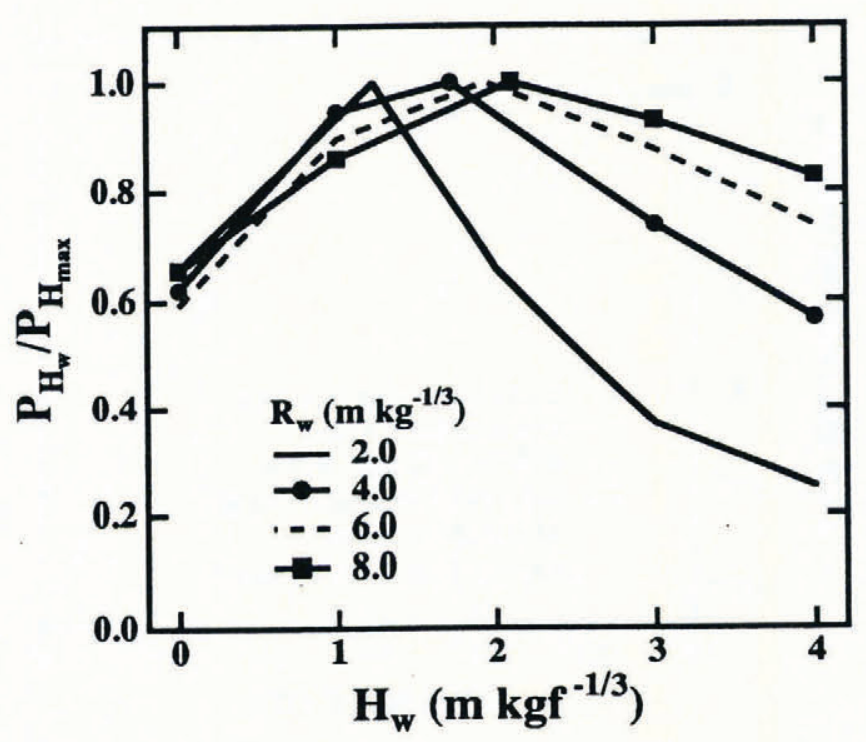

Fig. 4. The ratio of $P_{H_{\mathrm{w}}} / P_{H_{\max }}$ as a function of the scaled detonation height $H_{\mathrm{w}} . P_{H_{\mathrm{w}}}$ is the pressure at a specified scaled radius from ground zero, $R_{\mathrm{w}}$, produced by an explosive detonated at a scaled detonation height of $H_{\mathrm{w}}$, and $P_{H_{\max }}$ is as defined in Figure 3. Calculations were done using data from Ingram (1962) and Wisotski and Snyer (1966) summarized in O'Keeffe (1965) and Mellor (1985).

detonation height is not strictly correct, it probably results in an uncertainty of less than about $40 \%$ because of the relative insensitivity of snow-surface pressure to changes in detonation height, as discussed below.

The maximum snow-surface pressure at $R_{H_{\max }}$ is relatively insensitive to changes in the scaled detonation height, $H_{\max }$, for heights greater than $2 \mathrm{~m} \mathrm{kgf}^{-1 / 3}$ (Fig. 3). For example, the change in maximum surface pressure caused by changing $H_{\max }$ from 1.0 to $1.2 \mathrm{~m} \mathrm{kgf}^{-1 / 3}$ is about $260 \mathrm{kPa}$, but the change in the maximum surface pressure resulting from a change in $H_{\max }$ from 2.0 to $2.2 \mathrm{~m} \mathrm{kgf}^{-1 / 3}$ is only $12 \mathrm{kPa}$. Further changes in the maximum surface pressure are proportional to $\left(H_{\max }\right)^{-3.4}$. This insensitivity can also be seen in Figure 4 , which shows the ratio of the surface pressure at a scaled radius $R_{\mathrm{w}}$, caused by detonation at a scaled height $H_{\mathrm{w}}$, to the maximum surface pressure produced when the explosive is detonated at $H_{\max }, P_{H_{\mathrm{w}}} / P_{H_{\max }}$. The maximum surface pressure occurs when $P_{H_{\mathrm{w}}} / P_{H_{\max }}=1$, and $H_{\mathrm{w}}=H_{\max }$ and $R_{\mathrm{w}}=R_{H_{\max }}$. A scaled detonation height of $1.2 \mathrm{~m} \mathrm{kgf}^{-1 / 3}$ produces a maximum snow-surface pressure at a scaled radius from ground zero of $2 \mathrm{~m} \mathrm{kgf}^{-1 / 3}$. When the scaled radius is greater than $4 \mathrm{~m} \mathrm{kgf}^{-1 / 3}$, however, $H_{\max }$ remains about $2 \mathrm{~m} \mathrm{kgf}^{-1 / 3}$. This indicates that detonating an explosive at an $H_{\max }$ greater than about $2 \mathrm{~m} \mathrm{kgf}^{-1 / 3}$ does not significantly change the far field pressure at the snow surface. In addition, the pressure ratio increases by about $40 \%$ when the detonation height is increased from zero to $H_{\max }$. While this is significant, it is a relatively small effect when compared to an increase of an order of magnitude or more in the far field snow-surface pressure or particle acceleration that can result when the detonation is in the air instead of in the snow (Joachim, 1967; Gubler, 1977). 


\section{APPLICATIONS}

Our understanding of the response of a snow cover to explosive loading can be used to explain practical and experimental experiences of using explosives in snow. Four problems of particular interest include: using explosives to release snow-slab avalanches, remove snow cornices, excavate snow and transmit stresses through snow to an underlying object.

\section{Explosive release of snow slab avalanches}

Explosives are used to release soft snow slab avalanches by increasing the stresses in zones of critical weakness. These zones are generally located in a relatively weak layer that supports the snow slab along its basal plane. Experiments and practice have shown that suspending an explosive above the snow cover is more effective at producing slab avalanches than placing an explosive in the snow. The most effective height of detonation for a $1 \mathrm{kgf}$ charge has been found to be about 1 to $2 \mathrm{~m}$ (Gubler, 1977). This agrees with our finding that increasing the scaled detonation height above 1.5 to $2 \mathrm{~m} \mathrm{kgf}^{-1 / 3}$ does not significantly increase the maximum far field pressure on a snow surface. The physical detonation height for an explosive of larger weight than $1 \mathrm{kgf}$, that produces the same pressure as a $1 \mathrm{kgf}$ explosive at a given radius, may be selected according to Equation (1).

Ultimately, to obtain a given snow surface pressure or deformation within a specific radius from ground zero, the size and location of the detonation position of an explosive needs to be determined according to the maximum presure curve (Fig. 3) and Equation (1). For soft snow-slab avalanches, estimates of the minimum additional pressure needed to cause slab failure vary from a few Pascal to several $\mathrm{kPa}$ acting over a radius of from 10 to $150 \mathrm{~m}$ (Mellor, 1973, 1985; Gubler, 1977).

If higher pressures, or snow compaction and excavation are desired, then an explosive may be more effective when detonated in the snow. For example, in some instances a hard snow slab may be sufficiently strong that the stresses from an explosive detonated in air may not cause failure. In this situation, practical experience indicates that detonating an explosive in the snow cover will help create fractures in the slab along with activating critical zones of weakness in the slab's basal layer. The fractures allow the slab to break apart and slide under the influence of gravity. Because of the large loss of momentum that will occur by snow compaction, larger numbers of explosives detonated in the snow may be needed to cause a hard snow slab to fail, as compared to releasing a soft slab using explosives detonated in air.

\section{Snow cornice removal and snow excavation}

Other examples of the need to detonate an explosive in the snow cover include snow-cornice removal and snow excavation. To remove a snow cornice, explosives are usually buried at intervals in the snow along the crown of the ridge underlying the cornice and detonated simultaneously. This creates craters and fractures in the snow reducing its strength along the line of maximum tensile stress so that the weight of the cornice will cause it to fall. Experiments (Gubler, 1977) and our calculations of shock waves in snow indicate the zone of compaction for a $1 \mathrm{kgf}$ explosive in seasonal snow is about $1 \mathrm{~m}$, suggesting that an appropriate interval between explosive charges is about $2 \mathrm{~m}$ which is in good agreement with recommended practice (Perla and Martinelli, 1976).

Snow excavation may be used to remove stable snow from a slope to prevent it from failing as a wet slab in spring or to trench through snow. Here, the techniques employed are the same as those developed for mining. Explosives are buried in snow at closely spaced intervals and with sufficient weight to provide the necessary momentum to move the snow.

\section{Pressure transmission through snow}

Pressure transmission of shock or acoustic waves through a snow cover into an underlying object is extremely inefficient for uncompacted snow. The impulse from a shock is dissipated through inelastic deformation of the snow. Acoustic waves propagating in the snow are low intensity and the acoustic impedance match between snow and an underlying object is generally poor. Pressure transmission through snow can be significantly improved by increasing the impulse of an explosive sufficiently to compact the snow completely. Snow impedance, in its uncompacted state, is near that of air. Our calculations show that as the snow is compacted its impedance may increase by a factor of ten or more, more closely matching the impedance of the underlying ground. The continuous change in snow impedance upon compaction acts to impedance match an air shock to the ground, or other object, underlying the snow and results in increased pressure transmission. Our calculations and experiments, and recent experiments of others (personal communication from G. G. Leigh) indicate that pressure transmitted into snow-covered ground from an air shock, with sufficient impulse to compact the snow cover fully, can be enhanced by a factor of four or more as compared to snow-free ground.

\section{Predicting stresses in snow}

Quantitatively predicting the response of snow to explosive loading requires the use of models that describe shock and acoustic/seismic wave propagation in and over snow. Recent experimental and analytical work by Johnson and others (1993) provides a basis for determining shock-wave propagation and attenuation in snow for quite complicated loading situations. Rigidframe porous media models (Albert and Orcutt, 1990; Attenborough and Buser, 1988) can be used to describe the propagation of acoustic waves over snow. Elastic or inelastic porous media theory (Johnson, 1982) may be used to describe acoustic/seismic wave propagation in sintered snow.

\section{SUMMARY}

An explosive detonation in snow-covered terrain can produce shock waves that propagate in snow and in the 
air above the snow. The detonation will also produce acoustic waves that propagate through the interstitial pores in snow and in the ice frame. Dissipation of an explosive's impulse in snow is caused by momentum spreading and is most pronounced when snow is permanently compacted. Planar shock waves can experience a pressure reduction of over $90 \%$ within $0.05 \mathrm{~m}$ of an explosive with a pressure impulse of $3 \mathrm{kPa}$ and a peak pressure of $1 \mathrm{GPa}$. Spherical waves are even more severely attenuated. The impulse of an explosive detonated in the air above a snow cover is transferred into the snow primarily through waves propagating in the interstitial air pores, in the absence of inelastic snow compaction. The coupled motion of the air in the pore space to the ice frame is responsible for most of the stress in the ice frame near the snow/air interface.

Increasing the scaled detonation height of an explosive up to $2 \mathrm{~m} \mathrm{kgf}^{-1 / 3}$ above a snow cover increases the far field snow-surface pressures. Scaled detonation heights greater than about $2 \mathrm{~m} \mathrm{kgf}^{-1 / 3}$ have little additional effect.

Both shock and acoustic/seismic waves are propagated when an explosive is detonated in a snow-covered environment. Consequently, a complete description of the response of a snow cover to explosive loading will require that models of shock-wave propagation in snow be coupled to those describing acoustic/seismic wave propagation in snow.

\section{ACKNOWLEDGEMENTS}

We thank H. Conway and D. G. Albert for their helpful comments. This study was funded by DA Project 4A762784AT42, Cold Regions Engineering Technology; Work Unit CS/012, Attenuation of Shock Waves by Snow.

\section{REFERENCES}

Albert, D. G. and J. A. Orcutt. 1990. Acoustic pulse propagation above grassland and snow: comparison of theoretical and experimental waveforms. 7. Acoust. Soc. Am., 87(1), 93-100.

Attenborough, K. 1985. Acoustical impedance models for outdoor ground surfaces. 7. Sound Vib., 99, 521-544.

Attenborough, K. and O. Buser. 1988. On the application of rigidporous models to impedance data for snow. F. Sound Vib., 124, 315327.

Baker, W.E. 1973. Explosions in air. Austin, TX, University of Texas Press.

Dobratz, B. M. and P. C. Crawford. 1985. LLNL explosives handbook: properties of chemical explosives and explosive simulants. Livermore, CA, Lawrence Livermore National Laboratory. (Report UCRL-52997.)

Gubler, H. 1977. Artificial release of avalanches by explosives. f. Glaciol., 19(81), 419-429.

Ingram, L. F. 1962. Air blast in an Arctic environment. Vicksburgh, MS, USA Waterways Experiment Station. (Technical Report 2-399.)

Joachim, C. E. 1967. Shock transmission through ice and snow. Vicksburgh, MS, USA Waterways Experiment Station. (Technical Report 1794.)

Johnson, J. B. 1982. On the application of Biot's theory to acoustic wave propagation in snow. Cold Reg. Sci. Technol., 6(1), 49-60.

Johnson, J. B. 1991. Simple model of shock-wave attenuation in snow. $\mathcal{F}$. Glaciol., 37 (127), 303-312.

Johnson, J. B., D. J. Solie, J. A. Brown and E. S. Gaffney. 1993. Shock response of snow. 7. Appl. Phys., 73(10), Part I, $4852-4861$.

Mellor, M. 1973. Controlled release of avalanches by explosives. Symposium on Advances in Avalanche Technology, Reno, Nevada, 1972. U.S. Dep. Agric. For. Serv. Gen. Tech. Rep. RM-3, 37-49.

Mellor, M. 1985. Blasting and blast effects in cold regions. Part I: Air blast. CRREL Spec. Rep. 85-25.

O'Keeffe, D. 1965. Height of burst curves for snow. White Oak, MD, US Naval Ordnance Laboratory. (Report 64-24.)

Perla, R. I. and M. Martinelli, Jr. 1976. Avalanche handbook. Fort Collins, CO, USDA Forest Service. (Agriculture Handbook 489.)

Taylor, L. M. and D. P. Flanagan. 1987. PRONTO 2D: a two-dimensional transient solid dynamics program. Albuquerque, NM, Sandia National Laboratories. (Report Sand 86-0594.)

Wisotski, J. and W.H. Snyer. 1966. A study of the effects of snow cover on high explosive blast parameters. Denver, CO, University of Denver. Denver Research Institute. (Final Report on Contract N609217016.)

The accuracy of references in the text and in this list is the responsibility of the authors, to whom queries should be addressed. 